\title{
Comparing methods to calculate hospital-specific rates of early death or urgent readmission
}

\author{
Carl van Walraven MD MSc, Jenna Wong BSc MSc, Steven Hawken MSc, Alan J. Forster MD MSc
}

Competing interests: None declared.

This article has been peer reviewed.

Correspondence to: Carl van Walraven, carlv@ohri.ca

CMAJ 2012. DOI:10.1503 /cmaj.120801

\begin{abstract}
Background: Hospital readmissions are important patient outcomes that can be accurately captured with routinely collected administrative data. Hospital-specific readmission rates have been reported as a quality-of-care indicator. However, the extent to which these measures vary with different calculation methods is uncertain.
\end{abstract}

Methods: We identified all discharges from Ontario hospitals from 2005 to 2010 and determined whether patients died or were urgently readmitted within 30 days. For each hospital, we calculated 4 distinct observed-to-expected ratios, estimating the expected number of events using different adjustments for confounders (age and sex v. complete) and different units of analysis (all admissions v. single admission per patient).

Results: We included 3148648 admissions to hospital for 1802704 patients in 162 hospi-

$\mathrm{R}$ eadmission rates are used to gauge and compare hospital performance and have been reported around the world. ${ }^{1-4}$ These rates create great public interest and concern regarding the local quality of health care. A recently created Canadian website reporting indicators including readmission rates crashed when it experienced 15 times more hits that expected. ${ }^{5,6}$ Policy-makers in some jurisdictions have implemented programs linking readmission rates to reimbursement.?

The influence of the statistical methods used to calculate readmission rates has not been extensively explored. Variation exists in the methods used to calculate readmission rates: in Australia, patient-level covariates are not adjusted for; ${ }^{8}$ in the United States, Medicare uses a hierarchical model to adjust for patient age, sex and comorbidity, in addition to clustering of patients within hospitals. ${ }^{9}$ Furthermore, the patient populations included when calculating readmission rates vary, from a limited group of diagnoses in the US ${ }^{4}$ to almost all admissions to hospital in Great Britain. ${ }^{10}$ tals. Ratios adjusted for age and sex alone had the greatest variation. Within hospitals, ranges of the 4 ratios averaged $31 \%$ of the overall estimate. Readmission ratios adjusted for age and sex showed the lowest correlation (Spearman correlation coefficient 0.48-0.68). Hospital rankings based on the different measures had an average range of 47.4 (standard deviation 32.2) out of 162 .

Interpretation: We found notable variation in rates of death or urgent readmission within 30 days based on the extent of adjustment for confounders and the unit of analysis. Slight changes in the methods used to calculate hospital-specific readmission rates influence their values and the consequent rankings of hospitals. Our results highlight the caution required when comparing hospital performance using rates of death or urgent readmission within 30 days.
Therefore, the methods used to determine re admission rates vary extensively with no apparent consensus on how these statistics should be calculated. We calculated adjusted hospital-specific rates of death or urgent readmission within 30 days and hospital rankings, varying 2 key factors relevant to generating these statistics: the completeness of confounder adjustment and the inclusion of all admissions to hospital versus a single admission per patient. Our goal was to determine the reliability of early death or urgent readmission rates as an indicator of hospital performance.

\section{Methods}

\section{Study design and data sources}

We used population-based administrative databases to find patients discharged alive after admission to an Ontario hospital between Jan. 1, 2005, and Dec. 31, 2010. We used 3 population-based administrative databases that captured data for all residents of Ontario: the Discharge Abstract Database records all nonpsychiatric admissions; the Registered Persons Database records the dates of 
death for all residents of Ontario; and the National Ambulatory Care Reporting System records all visits to emergency departments.

The study was approved by the research ethics board of The Ottawa Hospital.

\section{Study population}

We used the Discharge Abstract Database to identify all adults (age $>17 \mathrm{yr}$ ) discharged to the community from acute care hospitals during the study period. We chose the period from Jan. 1, 2005, to Dec. 31, 2010, because it was the most recent time for which complete data were available.

Patients who were discharged from an acute care hospital and immediately admitted to another acute care hospital within 6 hours were considered interhospital transfers; this was counted as a single admission. We excluded patients discharged from obstetric or psychiatric services (excluded from the risk-adjustment model used for the study ${ }^{11}$ and identified by their patient service and major clinical category codes) and patients admitted to palliative care (most-responsible diagnosis code Z51.5 in the Canadian enhancement of the International
Classification of Diseases, 10th revision [ICD10-CA]). In addition, we excluded patients discharged to inpatient rehabilitation or long-term care facilities (because they, and their postdischarge care, are distinct from medical and surgical patients) and patients discharged from lowvolume hospitals (fewer than 50 discharges/yr) because estimates of their readmission rates would be highly variable. Finally, we excluded patients ineligible for health care coverage in Ontario, because we would be unable to completely capture their outcomes.

\section{Rates of death or urgent readmission within 30 days}

For all admissions that occurred during the study period, we determined whether people died or were urgently readmitted (i.e., an unplanned admission) to any hospital in Ontario within 30 days of discharge from the original hospital. All deaths were identified using the Registered Persons Database and were included regardless of cause. We identified urgent readmissions using the Discharge Abstract Database using the emergent status collected for each patient. We

Table 1: Characteristics of hospitals included in the study

\begin{tabular}{|c|c|c|c|}
\hline \multirow[b]{2}{*}{ Characteristic per hospital } & \multicolumn{3}{|c|}{ Hospital-specific average } \\
\hline & Median (IQR)* & Minimum & Maximum \\
\hline \multicolumn{4}{|l|}{ Hospital volume } \\
\hline Annual no. of discharges & $1142.8(427.8-5192.3)$ & 69.0 & 24341.8 \\
\hline \multicolumn{4}{|l|}{ Patients } \\
\hline Age, yr, mean & $63.5(60.9-67.0)$ & 19.8 & 75.4 \\
\hline Male sex, \% & $46.8 \quad(45.2-48.4)$ & 33.7 & 69.0 \\
\hline Charlson Comorbidity Index score ${ }^{14} \geq 1, \%$ & $34.4 \quad(29.3-39.8)$ & 10.5 & 62.6 \\
\hline Visits to emergency department in previous $6 \mathrm{mo}, \%$ & $55.4 \quad(46.5-63.9)$ & 19.8 & 76.8 \\
\hline Elective admissions in previous yr, \% & $(8.4-11.3)$ & 5.6 & 35.3 \\
\hline Emergent admissions in previous yr, \% & $32.1 \quad(27.0-37.7)$ & 12.9 & 50.1 \\
\hline \multicolumn{4}{|l|}{ Admissions } \\
\hline Emergent, \% & $82.4 \quad(70.2-90.0)$ & 19.4 & 98.8 \\
\hline Length of stay, $d$, mean & $(5.4-7.2)$ & 2.4 & 16.9 \\
\hline Admissions with any alternate level of care, $\%$ & $(1.4-3.6)$ & 0.0 & 38.7 \\
\hline Admissions with case-mix group score $\ddagger>0, \%$ & $28.0 \quad(20.7-33.2)$ & 2.9 & 45.5 \\
\hline $\mathrm{LACE}+\S$ score, mean & $49.0 \quad(43.8-54.6)$ & 18.2 & 63.1 \\
\hline \multicolumn{4}{|l|}{ Outcomes following discharge } \\
\hline Death or urgent readmission within $30 \mathrm{~d}, \%$ & $13.2(11.0-15.4)$ & 4.6 & 20.0 \\
\hline Death within $30 \mathrm{~d}, \%$ & $1.9 \quad(1.5-2.4)$ & 0.2 & 4.3 \\
\hline Urgent readmission within $30 \mathrm{~d}, \%$ & $12.2(10.2-14.1)$ & 4.1 & 19.3 \\
\hline \multicolumn{4}{|c|}{$\begin{array}{l}\text { Note: IQR = interquartile range. } \\
\text { "The values are medians of percentages or means for each hospital. } \\
\text { fRisk of death within } 30 \text { days or unplanned readmission, independent of factors known to influence this outcome; }{ }^{15} \text { higher scores } \\
\text { indicate higher risk. } \\
\text { §Risk of death within } 30 \text { days or unplanned readmission; }{ }^{11} \text { higher scores indicate higher risk. }\end{array}$} \\
\hline
\end{tabular}


excluded psychiatric admissions, obstetric admissions for delivery (ICD-10-CA codes O10-O16, O21-O26, O28-O37, O40-O46, O48, O60-O75, O85-092, O95 or O98-O99 with a sixth digit of 1 or 2, or Z37) and palliative admissions. Deaths and urgent readmissions were combined in previous studies of factors associated with readmission ${ }^{11}$ to avoid issues caused by competing events (i.e., patients who die cannot be readmitted).

We calculated hospital-specific rates of death or urgent readmission within 30 days stratified using 2 binary factors, for a total of 4 rates calculated per hospital. The first binary factor dealt with the completeness of adjustment. For one group (age-sex adjustment), we adjusted only for patient age and sex. For the other group (complete adjustment), we adjusted for all factors in the LACE+ index (Appendix 1, available at www.cmaj.ca/lookup/suppl/doi:10.1503/cmaj $.120801 /$-/DC1). ${ }^{11}$

The second binary factor was whether the admission to hospital or the patient was used as the unit of analysis. With the former (all admissions), all admissions were used in the calculation, meaning that a single patient could contribute multiple admissions to the rate. With the latter (single admission per patient), one admission per patient was selected randomly. We recently found that this distinction is important: the accuracy of predicting performance using rates of death or urgent readmission within 30 days declined significantly when all admissions were used (unpublished data). We reasoned that this could be due to patients with multiple acute admissions having characteristics that are not adequately captured by administrative data and that increase their risk of death or urgent readmission after discharge.

These factors resulted in 4 distinct measures: all admissions, adjusted for patient age and sex; a single admission per patient, adjusted for patient age and sex; all admissions, adjusted for all factors in the LACE+ index; and a single admission per patient, adjusted for all factors in the LACE+ index.

\section{Statistical analysis}

We expressed each of the 4 measures as an observed-to-expected ratio, in which the numerator was the number of observed events for the hospital, and the denominator was the number of expected events.

We calculated the number of expected events for all hospitals using logistic regression models. For the age- and sex-adjusted ratios, we determined the expected risk of an outcome for each person using a model derived from the study population; in this model, death or urgent readmission within 30 days was the outcome, and patient age and sex were the predictor variables. For the completely adjusted ratios, we used the LACE+ model to determine the expected numbers of events. We directly translated each person's LACE+ score into an expected risk of outcome (Appendix 1). In all situations, the patientspecific risks determined using the models were summed to calculate the expected number of events for each hospital.

We ranked hospitals using each of the 4 measures. We determined the association among the 4 measures, and the consequent rankings, using Spearman correlation coefficient. We compared hospital categorization into the highest ( $>$ 90th percentile), lowest $(<10$ th percentile) and middle (10-90th percentile) groups by each measure using weighted $\kappa$ scores. ${ }^{12}$

We used "standardized ranges" to quantify variation among and within the measures. We calculated the standardized range as the difference between the largest and smallest ratio divided by the overall summary ratio. Thus, the

Table 2: Observed-to-expected ratios for death or urgent readmission within 30 days for the 162 hospitals included in the study, calculated using 4 different measures*

\begin{tabular}{|lcc|}
\hline Measure & $\begin{array}{c}\text { Observed-to- } \\
\text { expected ratio, } \\
\text { mean } \pm \text { SD }\end{array}$ & $\begin{array}{c}\text { Observed-to- } \\
\text { expected ratio, } \\
\text { median (range) }\end{array}$ \\
\hline All admissions, adjusted for patient age and sex & $1.11 \pm 0.21$ & $1.10(0.45-1.77)$ \\
\hline Single admission per patient, adjusted for patient age and sex & $1.14 \pm 0.23$ & $1.13(0.44-1.83)$ \\
\hline All admissions, adjusted for all measurable factors & $0.94 \pm 0.11$ & $0.93(0.71-1.39)$ \\
\hline $\begin{array}{l}\text { Single admission per patient, adjusted for all measurable } \\
\text { factors }\end{array}$ & $0.94 \pm 0.12$ & $0.94(0.63-1.40)$ \\
\hline $\begin{array}{l}\text { Note: SD }=\text { standard deviation. } \\
\text { *The number of expected events was calculated by use of logistic regression models. Age- and sex-adjusted ratios calculated the } \\
\text { expected number of events after adjustment for patient age and sex; completely adjusted ratios used the LACE+ model to } \\
\text { determine the expected numbers of events. }\end{array}$ & \\
\hline
\end{tabular}


standardized range expresses the range of measure values as a proportion of the overall summary ratio. The overall summary ratio was calculated using a fixed-effects model that weighted observations by each ratio's variance estimates, which were calculated using Byar's approximation. ${ }^{13}$ We calculated standardized ranges in hospital-specific observed-to-expected ratios among the measures within each year, and among the 6 years within each observed-to-expected ratio. To rank hospitals using these measures, we examined the standardized ranges.

\section{Results}

During the study period, there were 6427407 separations (includes deaths and discharges) from acute-care hospitals in Ontario among people with valid health care numbers. Of the corresponding admissions to hospital, we excluded 3278759 (51.0\%) from our analysis: 265484 (4.1\%) patients died in hospital; 1295279 (20.2\%) admissions were for people under 18 years of age; $132671(2.1 \%)$ were psychiatric admissions; 895431 (13.9\%) were obstetric admissions; $16325(0.3 \%)$ were for palliative care; $670215(10.4 \%)$ patients were discharged to long-term care, rehabilitation or another hospital, or signed themselves out against medical advice; 1249 (0.02\%) were invalid (i.e., the Registered Persons Database documented a date of death for the health care number before the date of admission to hospital); and $2105(0.006 \%)$ were from low-volume hospitals. Thus, we included 3148648 admissions to 162 hospitals for 1802704 patients.

The characteristics of the admissions were diverse (Table 1). Hospitals had an annual mean of 3239 eligible discharges (range 69.024 341.8). Patients tended to be middle aged (median $63.5 \mathrm{yr}$ ), and one-third had at least 1 serious comorbidity. More than half of the patients had visited an emergency department in the 6 months before their admission (range $19.8 \%-76.8 \%$ ), and one-third had an urgent admission in the previous year (range 12.9\%$50.1 \%$ ). Most of the admissions were emergent (median $82.4 \%$ ), but the percentage varied widely among institutions (19.4\%-98.8\%). The median length of stay was 6 days, but this characteristic

Table 3: Variation in hospital-specific observed-to-expected ratios for death or urgent readmission within 30 days and their associated rankings

\begin{tabular}{|c|c|c|c|c|c|c|c|c|}
\hline \multirow[b]{2}{*}{ Variation } & \multicolumn{4}{|c|}{$\begin{array}{l}\text { Standardized ranges* for } \\
\text { observed-to-expected ratios (\%) }\end{array}$} & \multicolumn{4}{|c|}{$\begin{array}{l}\text { Hospital rankings based on } \\
\text { observed-to-expected ratiost }\end{array}$} \\
\hline & Mean \pm SD & $\begin{array}{l}\text { Median } \\
(\mathrm{IQR})\end{array}$ & Minimum & Maximum & Mean \pm SD & Median (IQR) & Minimum & Maximum \\
\hline \multicolumn{9}{|c|}{ Among measures within specific years } \\
\hline 2005 & $32.5 \pm 22.8$ & $28(18-42)$ & 7 & 232 & $43.3 \pm 30.0$ & $(20-61)$ & 0 & 143 \\
\hline 2006 & $30.0 \pm 18.7$ & $29(14-44)$ & 2 & 96 & $52.5 \pm 32.9$ & $(26-74)$ & 0 & 136 \\
\hline 2007 & $31.8 \pm 23.4$ & $28(14-41)$ & 2 & 157 & $54.4 \pm 33.3$ & $(30-75)$ & 3 & 159 \\
\hline 2008 & $30.5 \pm 18.7$ & $28(15-42)$ & 3 & 80 & $50.8 \pm 32.0$ & $45.5(28-68)$ & 2 & 145 \\
\hline 2009 & $31.9 \pm 22.8$ & $28(17-41)$ & 4 & 212 & $49.5 \pm 31.8$ & $42.5(26-70)$ & 0 & 151 \\
\hline 2010 & $32.0 \pm 23.8$ & $27(15-42)$ & 1 & 141 & $47.9 \pm 32.8$ & $(23-68)$ & 1 & 151 \\
\hline All years & $31.5 \pm 21.8$ & $28(16-42)$ & 1 & 232 & $47.4 \pm 32.2$ & $43.5(23-66)$ & 2 & 148 \\
\hline \multicolumn{9}{|c|}{ Among years within specific measures } \\
\hline $\begin{array}{l}\text { Age-, sex-adjusted, all } \\
\text { admissions }\end{array}$ & $27.5 \pm 19.7$ & $22(15-35)$ & 4 & 154 & $45.2 \pm 31.4$ & $(22-62)$ & 1 & 155 \\
\hline $\begin{array}{l}\text { Age-, sex-adjusted, } \\
\text { single } \\
\text { admission/patient }\end{array}$ & $49.8 \pm 35.3$ & $43(26-66)$ & 8 & 273 & $61.0 \pm 38.7$ & $51.5(31-81)$ & 1 & 161 \\
\hline $\begin{array}{l}\text { Complete adjustment, } \\
\text { all admissions }\end{array}$ & $26.0 \pm 18.4$ & $21(14-33)$ & 3 & 131 & $62.8 \pm 37.0$ & $(34-87)$ & 4 & 161 \\
\hline $\begin{array}{l}\text { Complete adjustment, } \\
\text { single } \\
\text { admission/patient }\end{array}$ & $47.8 \pm 37.0$ & $38(24-59)$ & 7 & 288 & $75.8 \pm 40.2$ & $72 \quad(44-103)$ & 3 & 161 \\
\hline $\begin{array}{l}\text { Note: IQR = interquartile rar } \\
\text { *Range in observed-to-expe } \\
\text { calculated using a fixed-effe } \\
\text { tThe maximum range in ran }\end{array}$ & $\begin{array}{l}\mathrm{SD}=\text { standard } \\
\text { ratios for read } \\
\text { nodel that wei } \\
\text { ys is } 162 \text { (i.e., } \mathrm{th}\end{array}$ & $\begin{array}{l}\text { iation. } \\
\text { sion within e } \\
\text { ed observatio } \\
\text { otal number }\end{array}$ & hospital as & percentage $c$ & $\begin{array}{l}\text { e overall read } \\
\text { were calculat }\end{array}$ & $\begin{array}{l}\text { n ratio for that hos } \\
\text { ng Byar's approxim }\end{array}$ & $\begin{array}{l}\text { pital. The ov } \\
\text { ation. }{ }^{14}\end{array}$ & all ratio was \\
\hline
\end{tabular}


also varied widely (2.4-16.9 d) among hospitals. The proportion of discharges followed by a death or urgent readmission within 30 days ranged from $4.6 \%$ to $20.0 \%$ (median $13.2 \%$ ). Readmissions were more common than deaths (Table 1).

\section{Outcomes}

Each of the measures showed notable variation among hospitals (Table 2). Ratios for which adjustment was limited to patient age and sex showed the greatest variation among hospitals, with standard deviations — which measured interhospital variability in ratio values - that were almost double those of the ratios calculated using complete adjustment. The overall mean and median readmission ratios had the same values when complete adjustment was used.

We observed extensive variation within hospital-specific comparisons (Table 3). For each year, the range of observed-to-expected ratios within specific hospitals averaged $31 \%$ of the overall summary ratio, extending from a minimum of $1 \%$ to a maximum of $232 \%$ (Table 3 ). Standardized ranges were very strongly associated with the number of patients discharged each year from the hospital, with standardized ranges increasing by $3.3 \%$ with every decrease of 1000 in the number of discharges $(p<0.001)$. This trend

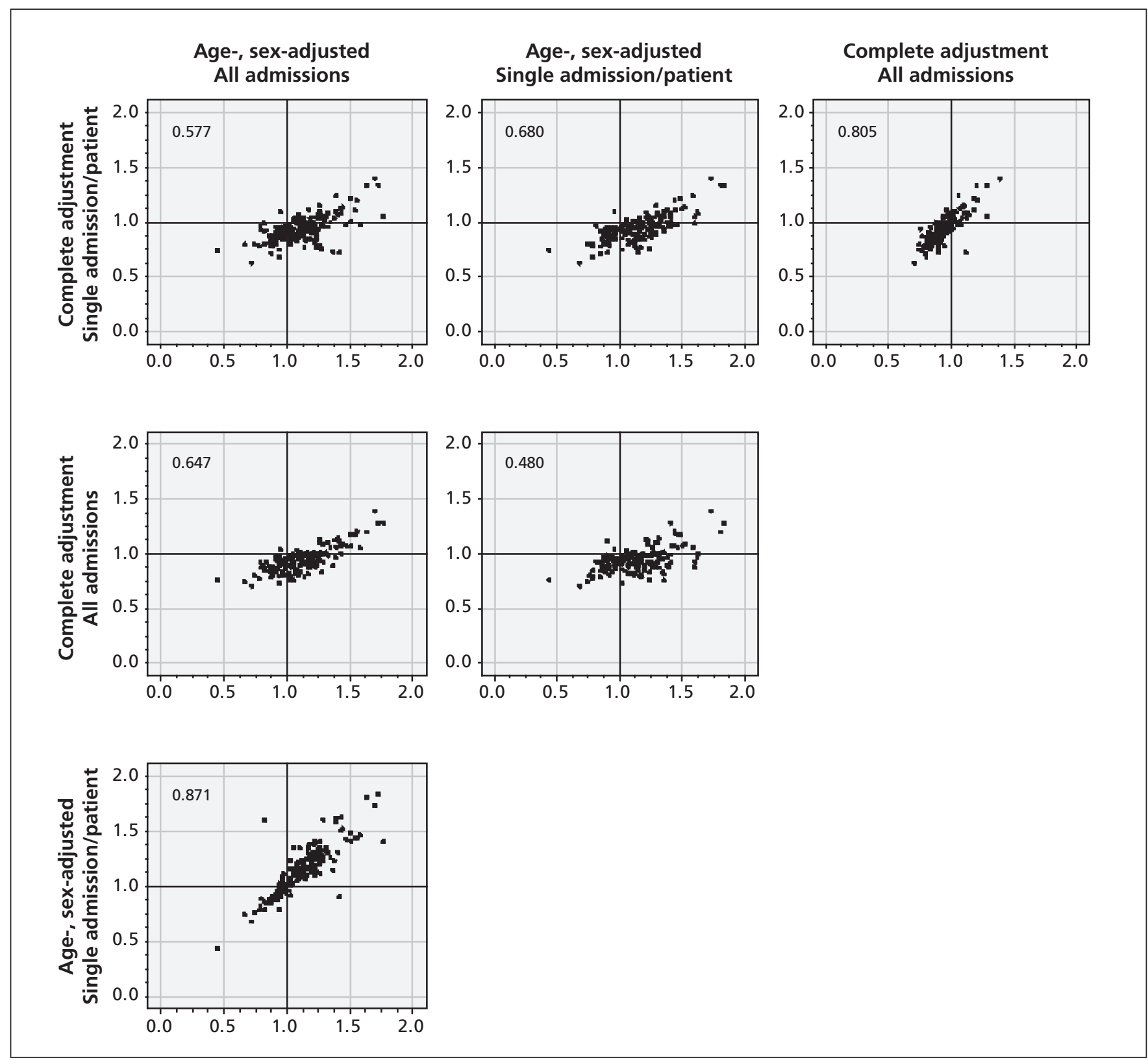

Figure 1: Comparison of values for observed-to-expected ratios for death or urgent readmission within 30 days determined for 162 hospitals using 4 different methods of calculation. The Spearman correlation coefficient is presented in the top left corner of each plot. The panels are aligned as rows and columns by categories. 
could explain why measures that used a small number of discharges (i.e., those limited to a single discharge per patient) had notably large mean standardized ranges (e.g., 48 and 50; Table 3).

Hospital rankings determined by use of readmission ratios varied extensively (Table 3 ). The mean range in rankings for all years based on the 4 measures was 47.4 (standard deviation [SD] 32.2) (Table 3). Thus, on average, the range in a hospital's ranking calculated using the 4 measures was $29.3 \%$ of the entire ranking scale (i.e., 162). Among years, rankings based on the same measure showed very similar ranges; those based on the completely adjusted, single admission per patient had the highest mean range $(75.8, \mathrm{SD}$ 40.2) (Table 3).

\section{Comparison of calculation methods}

We directly compared the 4 methods for calculating ratios for death or urgent readmission within 30 days (Figure 1) and their associated rankings (Figure 2). The greatest correlation existed between the 2 age- and sex-adjusted ratios (Spearman correlation coefficient 0.871) and the 2 completely adjusted ratios (Spearman correlation coefficient 0.805 ). Comparison between ratios that used different adjustment methods (i.e., age- and sex-adjustment v. com-
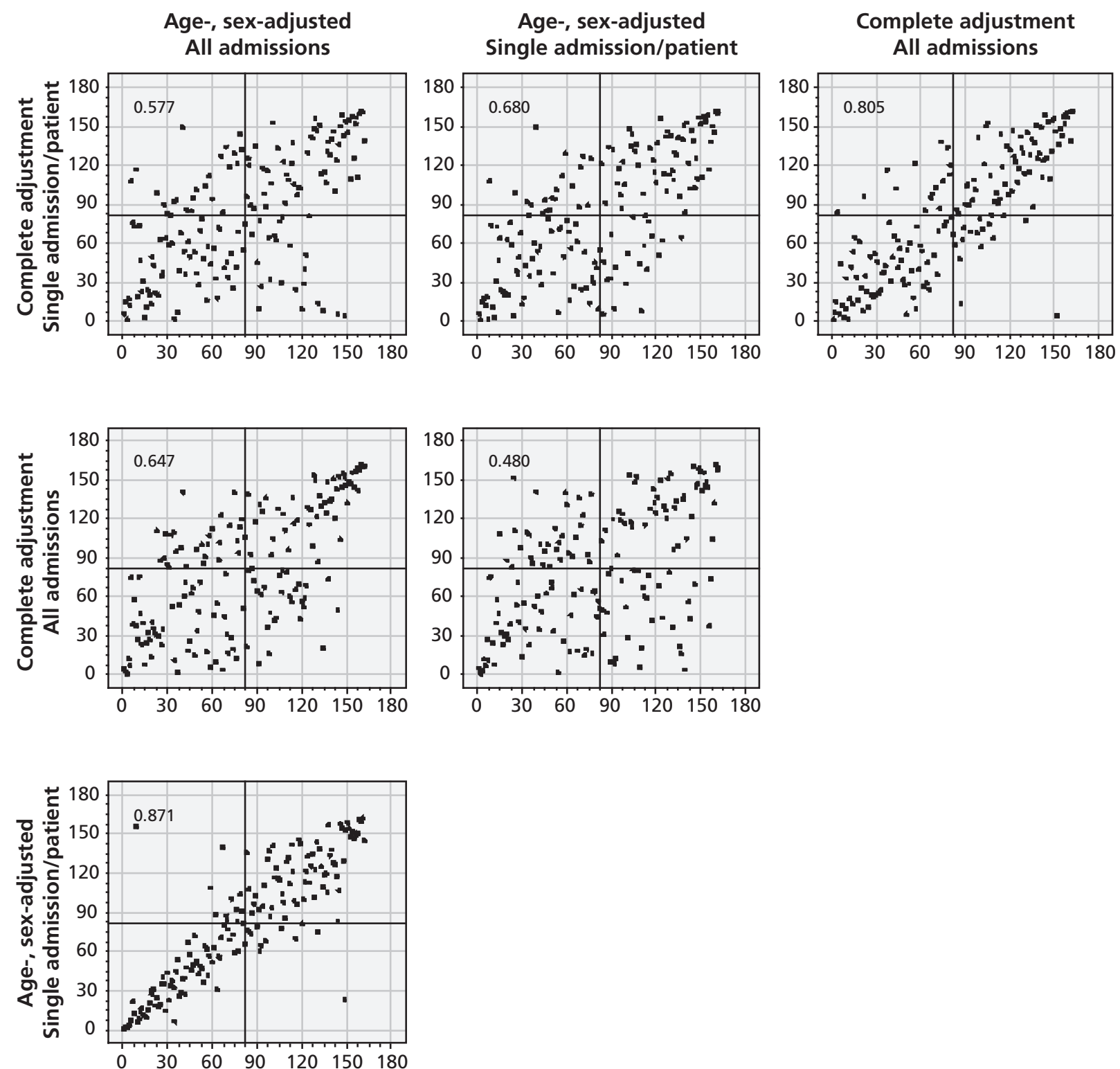

Figure 2: Comparison of hospital rankings determined using 4 different methods of calculating observed-to-expected ratios for death or urgent readmission within $\mathbf{3 0}$ days for the 162 hospitals included in the study. The Spearman correlation coefficient is presented in the top left corner of each plot. The panels are aligned as rows and columns by categories. 
plete adjustment) showed notably less correlation (Spearman correlation coefficient 0.4800.680). Comparing hospital rankings based on these ratios showed greater scatter among hospitals (Figure 2) and, as expected, resulted in the same Spearman correlation coefficients.

Hospital rankings also varied by method (Table 4). The greatest disagreement occurred between ratios that used different adjustment methods. All other comparisons showed between $16.7 \%$ and $21.0 \%$ of hospitals being grouped into a different ranking category, with weighted $\kappa$ scores ranging from 0.44 to 0.62 .

\section{Interpretation}

We found notable variation in hospital-specific rates based on the extent of adjustment for confounders and whether the unit of analysis used in the calculation was the admission to hospital (in which all admissions are included) or the patient (for which a single admission is randomly selected). This resulted in extensive variation in the hospital rankings determined using these rates.

Our results highlight the caution required when comparing hospital performance using rates of death or urgent readmission within 30 days. To measure quality of care, one would ideally measure the number of avoidable readmissions. Because accurately doing so requires the collection of primary data, ${ }^{16}$ total rates of unplanned readmissions within 30 days - calculable using routinely collected data - are used. Standard methods do not exist for calculating rates of death after discharge or urgent readmission.

Although we found notable disagreement among the 4 measures, the best method for calculating rates of death or urgent readmission within 30 days remains unclear. All-cause readmissions are a surrogate measure for "avoidable readmissions," because only about one-quarter of urgent readmissions are deemed potentially avoidable. ${ }^{16}$ Therefore, the rate of death or urgent readmission within 30 days with the strongest association with avoidable readmission rates would be best. The only study comparing hospital-specific death or urgent readmission and avoidable readmission found no such association. ${ }^{17}$ If other studies confirm this result, the use of 30-day readmission rates to measure quality of care should be questioned.

Until we know how best to measure rates of avoidable readmission using administrative data, we need to rely on face validity to determine which method is preferable for measuring hospital-specific postdischarge outcomes. We believe that measures best able to adjust for potential confounders using validated prediction models are preferable. Such measures could use internally developed or previously published models, such as LACE.$+{ }^{11}$ Regardless, the model's accuracy should be clearly stated to inform readers of its effectiveness for levelling the playing field among hospitals.

Table 4: Comparison of hospital rankings using different measures of death or urgent readmission within 30 days

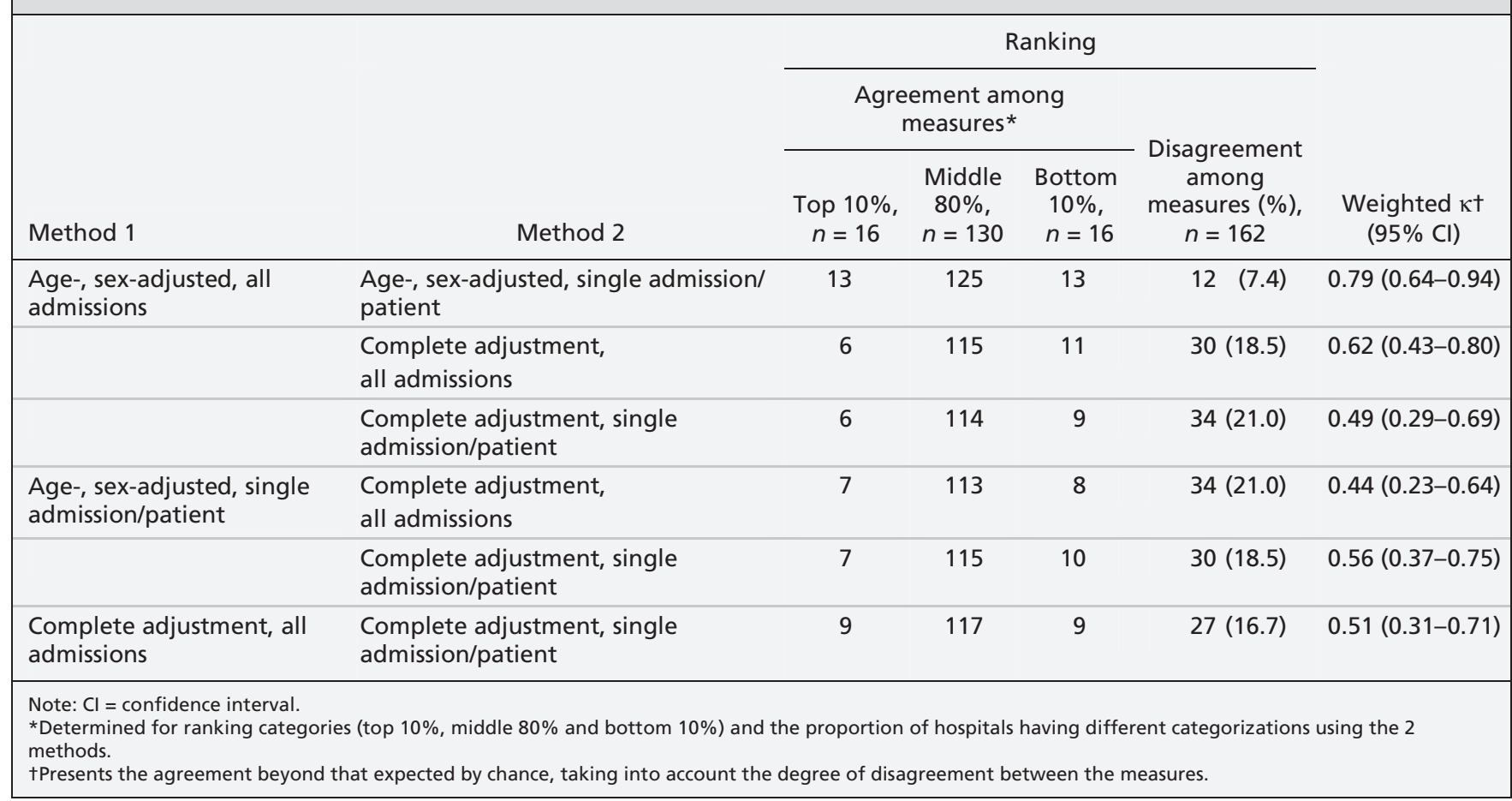


Our study has several notable findings. First, hospital-specific rankings varied extensively. Rankings changed by almost a complete tertile depending on the method used to calculate the rates of death or readmission. Second, in contrast to ratios, we found that hospital rankings tended to exaggerate interinstitutional differences. Third, variation in hospital-specific rates of readmission was very sensitive to the number of discharges used in the calculation. Thus, randomly selecting a single admission per patient could increase the quality of adjustment (because models predicting rates of death or urgent readmission within 30 days are more accurate with a single admission per patient [unpublished data]), but could also exacerbate the variation in measures with the decrease in sample size.

\section{Limitations}

Our analysis was limited to Ontario, and we are uncertain how generalizable our results are to other jurisdictions. We are also uncertain how our results apply to the pediatric, obstetric and psychiatric populations, which comprised $36 \%$ of all admissions to hospital during the study period. It is possible that population-based variability in readmission rates would be lower in regions with greater numbers of discharges per hospital.

\section{Conclusion}

We found notable variation in rates of death or urgent readmission within 30 days based on the extent of adjustment for confounders and the unit of analysis used in the calculation. In addition, slight changes in the methods used to calculate hospital-specific rates of readmission greatly influenced their values and the consequent ranking of hospitals. These observations should be considered when comparing hospital performance using rates of readmission.

\section{References}

1. Quality monitor: Health Quality Ontario: 2011 report on Ontario's health system. Toronto (ON): Health Quality Ontario; 2011.

2. The Information Centre for Health and Social Care. Hospital episode statistics: emergency readmissions to hospital within 28 days of discharge. Leeds (UK): The Centre; 2011.

3. Australian Institute of Health and Welfare. Hospital performance: readmissions following surgery. Canberra (AU): The Institute; 2012. Available: www.aihw.gov.au/hospital-performance-surgery -readmissions/ (accessed 2012 Feb. 2).

4. US Department of Health and Human Services. Hospital compare. Washington (DC): The Department; 2012. Available: www.hospitalcompare.hhs.gov/. (accessed 2012 Feb. 2).
5. Branswell H. Online hospitals rating tool launches, then crashes. The Globe and Mail [Toronto (ON)] 2012 Apr. 6; Sect. L:6.

6. Tam P. Region's hospitals fare poorly on patient returns. The Ottawa Citizen 2012 Apr 5. Available: www2.canada.com/ottawa citizen/news/story.html?id=5dc8261f-b387-4bbc-aabd-320334 c5ddb3 (accessed 2012 Aug. 15).

7. Kowalczyk L. State to penalize hospitals that readmit too many patients. The Boston Globe [Boston (MA)] 2011 Sep 22.

8. Australian Institute of Health and Welfare. Meteor Metadata Online Registry. National Healthcare Agreement: PI 43Unplanned/unexpected readmission within 28 days of selected surgical admissions, 2011. Canberra (AU): The Institute; 2012.

9. US Department of Health \& Human Services. Statistical methods used to calculate rates. Washington (DC): The Department; 2012.

10. The Information Centre for Health and Social Care. Compendium of population health indicators: emergency readmissions to hospital within 28 days of discharge. Leeds (UK): The Centre; 2011 .

11. van Walraven C, Wong J, Forster AJ. LACE+ - an extension of a validated index to predict early death or unplanned readmission following hospital discharge using administrative data. Open Medicine 2012;6:80-9.

12. Fleiss JL, Cohen J, Everitt BS. Large-sample standard errors of kappa and weighted kappa. Psychol Bull 1969;72:323-7.

13. Breslow NE, Day NE. Rates and rate standardization. Statistical methods in cancer research: volume II-the design and analysis of cohort studies. IARC Sci Publ 1987;(82):1-406.

14. Charlson ME, Pompei P, Ales KL, et al. A new method of classifying prognostic comorbidity in longitudinal studies: development and validation. J Chronic Dis 1987;40:373-83.

15. van Walraven C, Wong J, Forster AJ. Derivation and validation of a case-mix groups based diagnostic score to predict 30-day death or urgent hospital readmission. Open Medicine 2012;6 :90-100.

16. van Walraven C, Jennings A, Forster AJ. A Meta-analysis of hospital 30-day avoidable readmission rates. J Eval Clin Pract. In press.

17. van Walraven C, Jennings A, Taljaard M, et al. Incidence of potentially avoidable hospital readmission and its relationship to all-cause urgent readmissions. CMAJ 2011;183:E1067-72.

Affiliations: From the Faculty of Medicine (van Walraven, Forster), University of Ottawa; the Clinical Epidemiology Program (van Walraven, Wong, Hawken, Forster), Ottawa Hospital Research Institute, Ottawa, Ont.; and the Institute for Clinical Evaluative Sciences (van Walraven, Wong, Hawken, Forster), Toronto, Ont.

Contributors: The study was conceived by Carl van Walraven and Alan Forster. Jenna Wong created the analytical dataset and conducted the initial analyses under the supervision of Steven Hawken, who also directed the advanced analyses in the paper. Carl van Walraven wrote the manuscript, which was revised by all authors. All of the authors approved the final version submitted for publication.

Acknowledgement: This study was supported by the Department of Medicine, University of Ottawa. Carl van Walraven had full access to all of the data in the study and takes responsibility for the integrity of the data and the accuracy of the data analysis. Steven Hawken has received a doctoral research award from the Canadian Institutes of Health Research.

Disclaimer: This study was supported by the Institute for Clinical Evaluative Sciences (ICES), which is funded by an annual grant from the Ontario Ministry of Health and LongTerm Care (MOHLTC). The opinions, results and conclusions reported in this paper are those of the authors and are independent from the funding sources. No endorsement by ICES or the Ontario MOHLTC is intended or should be inferred. 